\title{
Characterization of iron speciation in urban and rural single particles using XANES spectroscopy and micro X-ray fluorescence measurements: investigating the relationship between speciation and fractional iron solubility
}

\author{
M. Oakes ${ }^{1}$, R. J. Weber ${ }^{1}$, B. Lai ${ }^{2}$, A. Russell ${ }^{3}$, and E. D. Ingall ${ }^{1}$ \\ ${ }^{1}$ School of Earth and Atmospheric Sciences, Georgia Institute of Technology, Atlanta, Georgia 30332, USA \\ ${ }^{2}$ Advanced Photon Source, Argonne National Laboratory, Argonne, Illinois 60439, USA \\ ${ }^{3}$ School of Civil \& Environmental Engineering, Georgia Institute of Technology, Atlanta, Georgia 30332, USA \\ Correspondence to: M. Oakes (michelle.oakes@eas.gatech.edu)
}

Received: 18 July 2011 - Published in Atmos. Chem. Phys. Discuss.: 11 August 2011

Revised: 4 December 2011 - Accepted: 17 December 2011 - Published: 16 January 2012

\begin{abstract}
Soluble iron in fine atmospheric particles has been identified as a public health concern by participating in reactions that generate reactive oxygen species (ROS). The mineralogy and oxidation state (speciation) of iron have been shown to influence fractional iron solubility (soluble iron/total iron). In this study, iron speciation was determined in single particles at urban and rural sites in Georgia USA using synchrotron-based techniques, such as X-ray Absorption Near-Edge Structure (XANES) spectroscopy and microscopic X-ray fluorescence measurements. Soluble and total iron content (soluble + insoluble iron) of these samples was measured using spectrophotometry and synchrotron-based techniques, respectively. These bulk measurements were combined with synchrotron-based measurements to investigate the relationship between iron speciation and fractional iron solubility in ambient aerosols. XANES measurements indicate that iron in the single particles was present as a mixture of $\mathrm{Fe}$ (II) and $\mathrm{Fe}$ (III), with $\mathrm{Fe}$ (II) content generally between 5 and $35 \%$ (mean: $\sim 25 \%$ ). XANES and elemental analyses (e.g. elemental molar ratios of single particles based on microscopic X-ray fluorescence measurements) indicate that a majority (74\%) of iron-containing particles are best characterized as Al-substituted Fe-oxides, with a Fe/Al molar ratio of 4.9. The next most abundant group of particles $(12 \%)$ was Fe-aluminosilicates, with $\mathrm{Si} / \mathrm{Al}$ molar ratio of 1.4. No correlation was found between fractional iron solubility (soluble iron/total iron) and the abundance of Alsubstituted Fe-oxides and $\mathrm{Fe}$-aluminosilicates present in single particles at any of the sites during different seasons, suggesting solubility largely depended on factors other than differences in major iron phases.
\end{abstract}

\section{Introduction}

Iron is an important component in atmospheric aerosols due to its potential impacts on human health (Smith and Aust, 1997). Adverse health effects associated with aerosols, such as cell and DNA damage, can stem from toxic levels of reactive oxygen species (ROS; e.g. hydrogen peroxide, hydroxyl radical, superoxide anion and organic peroxides, etc.) that form as a consequence of redox cycling of trace metals (Kelly, 2003; Vidrio et al., 2008). In comparison to other trace metals, iron has been reported as a significant source of ROS via metal-mediated pathways (Shafer et al., 2010; Smith and Aust, 1997; Zhang et al., 2008). The role of metals in adverse health impacts associated with aerosols depends largely on the fraction of total metal content that is readily soluble (Costa and Dreher, 1997; See et al., 2007; Valavanidas et al., 2008), thus, primary factors and mechanisms that alter iron aerosol solubility must be understood to further link aerosol iron to adverse health effects.

A growing body of knowledge has emerged on various control factors that impact iron aerosol solubility. Soluble iron in aerosols varies between 0 to $80 \%$ of total iron, showing no general trend with total iron concentration (Mahowald et al., 2005). While several chemical mechanisms and physical particle properties have been shown to influence iron solubility, there is still significant uncertainty on the primary factors that control fractional iron solubility (Baker and Croot, 2010). Modeling, laboratory and field studies have suggested that iron particles in dust may undergo atmospheric transformations (e.g. acid-processing) that may enhance fractional iron solubility (Meskhidze et al., 2005; Shi 
et al., 2009). On the other hand, Baker and Jickells (2006) observed no relationship between atmospheric acid processing and iron solubility in coarse and fine crustal particles in a marine environment, but instead observed a relationship between increasing fractional iron solubility and decreasing dust mass concentration, which was likely accompanied by decreasing particle size. In this particular study, the observed increase in fractional iron solubility was attributed to the large surface area available for iron dissolution that is characteristic of small particles (e.g. large surface area to volume ratio). However, Shi et al. (2010) later demonstrated that differences in particle size alone cannot explain the increase in fractional iron solubility observed in Baker and Jickells (2006), suggesting that other processes (e.g. acid-processing or mixing with other anthropogenic particles) may play a more dominant role or work synergistically with particle size to promote fractional iron solubility. A few recent laboratory studies have observed a strong relationship between iron speciation and fractional iron solubility in crustal and industrial fly ash particles (Journet et al., 2008; Cwiertny et al., 2008; Schroth et al., 2009). Cwiertny et al. (2008) showed that $\mathrm{Fe}(\mathrm{II})$-containing solid phase minerals may contribute to a significant portion of soluble iron in crustal sources. In addition, Schroth et al. (2009) showed that soluble iron content from industrial combustion sources, comprised mainly of iron sulfates, was significantly greater ( $\sim 80 \%$ of total iron) than the soluble content of crustal particles ( $\sim 0.04-3 \%$ of total iron), which were mainly comprised of iron oxides and silicates. These results are also consistent with aerosol data from a field study in Korea that showed enhanced fractional iron solubility in anthropogenic combustion sources rather than crustal sources (Chuang et al., 2005). However, there was insufficient data to determine whether unique speciation or acid-processing of iron in the combustion particles caused enhanced solubility. In addition, other studies have shown a positive relationship between organically-complexed iron (iron oxalate complexes) and fractional iron solubility (Paris et al., 2011). Furthermore, Furukawa et al. (2011) demonstrated that a majority of oxalate in ambient samples from Japan exists as metal complexes. Although the relationship between iron speciation and fractional iron solubility has been established in source particles (e.g. crustal and industrial), it is not clear in ambient particles. A comprehensive knowledge of iron speciation in relation to solubility in urban and rural aerosols would help to further understand its association with public health.

Relatively few analytical tools are available to provide detailed characterization of iron, which are described in detail by Majestic et al. (2007). Typically, studies of aerosols rely upon chemical extractions or spectroscopic techniques that provide oxidation and/or mineralogy information on bulk properties of iron in a sample. Spectrophotometry (e.g. ferrozine) and high performance liquid chromatography (HPLC) have been used to quantify $\mathrm{Fe}(\mathrm{II})$ and $\mathrm{Fe}(\mathrm{III})$ in bulk aerosol samples, but yield little information on mineral- ogy (Johansen et al., 2000; Zhuang et al., 1992). Mossbauer spectroscopy has been successfully used to directly characterize the oxidation state and mineralogy in aerosol samples (Hoffmann et al., 1996); however, collection of aerosol over a several month period is required to obtain sufficient mass for analysis $(\sim 1 \mathrm{~g})$. Recent innovations in synchrotron-based $\mathrm{X}$ ray absorption spectroscopy, specifically X-ray Absorption Near Edge Structure (XANES) and Extended X-ray Absorption Fine Structure (EXAFS) spectroscopies, have made it possible to explore both the oxidation state and mineralogy of iron. These methods require minimal sample preparation and are capable of single particle analysis. XANES and EXAFS have been widely used to probe iron speciation in soil samples (Marcus et al., 2008; Prietzel et al., 2007). Werner et al. (2007) recently extended EXAFS to atmospheric aerosols to identify oxidation state and mineralogy of chromium in urban California. A few studies have demonstrated the feasibility and benefits of synchrotron-based X-ray spectroscopic techniques using a low energy $\mathrm{X}$-ray beam for the analysis of iron in aerosol samples, but primarily focused on oxidation state characterization (Majestic et al., 2007; Takahama et al., 2008). In this study, particles collected on Teflon filters from urban and rural sites were investigated using synchrotron-based methods, XANES and microscopic X-ray fluorescence, to characterize the oxidation state, elemental association and mineralogy of single iron-containing particles. Soluble iron was quantified using the ferrozine method (Stookey, 1970) to investigate the link between speciation and solubility properties.

\section{Methods}

\subsection{Sample collection and storage}

Iron particles collected on Teflon filters (Whatman, Piscataway, New Jersey: $47 \mathrm{~mm}$-diameter, $2 \mu \mathrm{m}$ pore size) were analyzed using XANES and microscopic X-ray fluorescence. Twenty-four hour integrated $\mathrm{PM}_{2.5}$ filters were collected during different seasons at three urban sites and one rural site (Table 1) for the ongoing Assessment of Spatial Aerosol and Composition in Atlanta (ASACA) air quality study (Butler et al., 2003) and used in this analysis. Breifly, ambient air at a nominal flow rate of $16.71 \mathrm{~min}^{-1}$ was pulled through a cyclone (URG, Chapel Hill, North Carolina USA), selecting for particles with an aerodynamic diameter less than $2.5 \mu \mathrm{m}$ $\left(\mathrm{PM}_{2.5}\right)$, then directed through a series of two annunlar glass denunders (URG, Chapel Hill, North Carolina USA), removing acidic and alkaline gases. The particles were then collected onto the Teflon filter (Whatman, Piscataway, New Jersey: $47 \mathrm{~mm}$-diameter, $2 \mu \mathrm{m}$ pore size). Samples were stored in sealed polyethylene bags in a dark freezer $\left(\sim-20^{\circ} \mathrm{C}\right) \mathrm{im}-$ mediately after collection and were analyzed within 1 to 11 months. Because iron is non-volatile, sampling artifacts are likely associated with changes in iron oxidation state during 
Table 1. ASACA filter information.

\begin{tabular}{lllll}
\hline ASACA sample site & Site Type & Local Sources & $\begin{array}{l}\text { Winter } \\
\text { Date }\end{array}$ & $\begin{array}{l}\text { Summer } \\
\text { Date }\end{array}$ \\
\hline $\begin{array}{l}\text { Fire Station } 8 \\
\text { Atlanta, GA (urban) }\end{array}$ & Industrial & $\begin{array}{l}\text { Rail yard } \\
\text { Diesel Traffic }\end{array}$ & $1 / 28 / 10$ & $6 / 3 / 09$ \\
\hline $\begin{array}{l}\text { Fort McPherson } \\
\text { Atlanta, GA (urban) }\end{array}$ & $\begin{array}{l}\text { Commercial/ } \\
\text { Residential }\end{array}$ & $\begin{array}{l}\text { Major Interstate } \\
\text { Mobile }\end{array}$ & $2 / 10 / 09$ & $6 / 8 / 09$ \\
\hline $\begin{array}{l}\text { South Dekalb } \\
\text { Atlanta, GA (urban) }\end{array}$ & Commercial/ & Major Interstate & $11 / 11 / 08$ & $9 / 9 / 09$ \\
\hline $\begin{array}{l}\text { Fort Yargo } \\
\text { Winder, GA(rural) }\end{array}$ & State Park & Forested Region & $11 / 29 / 09$ & $7 / 4 / 09$ \\
\hline
\end{tabular}

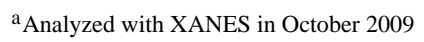

b Analyzed with XANES in February 2010

sample storage. Majestic et al. (2006) studied this specific artifact in aerosol samples and observed minimal Fe(II) loss on samples stored in a dark freezer for periods up to 6 months. In addition, Takahama et al. (2008) found no evidence for significant $\mathrm{Fe}(\mathrm{II})$ loss in samples stored in freezing temperatures over extended periods of time ( $>1$ year). Although $\mathrm{Fe}$ (II) loss due to chemical conversion is possible on these samples, it is not expected to be significant based on the sample storage time and conditions employed in this study. Before XANES and solubility analysis, filter samples were cut with ceramic scissors into half portions with each portion used for either synchrotron-based analyses or fractional iron solubility measurements.

\subsection{Single particle analysis: synchrotron-based X-ray spectroscopy}

Synchrotron-based X-ray spectroscopy is based on the principle that every element has characteristic absorption edges that correspond to the binding energy of electrons in individual quantized shells (e.g. $\mathrm{K}, \mathrm{L}_{2}$, and $\mathrm{L}_{3}$ ). In this technique, incident X-rays of sufficient energy bombard atoms, ejecting the electrons from an electron shell. Subsequently, an outer shell electron may relax into the vacated position, emitting a characteristic fluorescence signal. K-edge XANES spectroscopy, used in this study, specifically explores the absorption edge associated with the innermost, K-shell electron. The ejected electrons of the innermost K-shell interact with neighboring atoms. These interactions are influenced by the type, oxidation state and structural arrangement of atoms in a particle and are reflected in XANES spectra (Ingall, 2011). Thus, XANES spectra provide information on both oxidation state and the mineralogical structure associated with the element of interest.

A total of 221 iron-containing particles deposited on the Teflon filters were analyzed on the 2-ID-D beamline at the
Advanced Photon Source at Argonne National Laboratory in Argonne, Illinois, USA. The 2-ID-D beamline uses an energy dispersive Si-drift detector (Vortex EM, with a $50 \mathrm{~mm}^{2}$ sensitive area, and a $12.5 \mu \mathrm{m}$ Be window; SII NanoTechnology, Northridge CA, USA) to measure X-ray fluorescence of the sample. All measurements were conducted under a helium atmosphere in order to minimize absorption and fluorescence artifacts caused by low- $\mathrm{Z}$ elements in air. A randomly selected area of each filter sample $\left(\sim 0.5 \mathrm{~cm}^{2}\right)$ was placed over a slot of an aluminum sample mount for direct spectroscopic analysis of the iron particles on the filter. The sample was initially analyzed in microscopic X-ray fluorescence mode to identify regions on the filter with detectable iron concentrations (e.g. iron-containing particles). In this mode, a monochromatic X-ray beam with a diameter of $\sim 400$ nanometers was scanned over a filter area (typically $\sim 40 \times 40 \mu \mathrm{m}$ ) at a step size of $0.4 \mu \mathrm{m}$ and $0.4 \mathrm{~s} \mathrm{dwell}$ to produce an elemental distribution map of the filter. These maps were produced by setting the X-ray energy to $7200 \mathrm{eV}$, which allowed for the collection of K-edge X-ray fluorescence data on elements with masses from aluminum to iron (Al, Si, P, S, Cl, K, Ca, Ti, V, Cr, Mn, and Fe). The fluorescence data was converted into concentration data $\left(\mu \mathrm{g} \mathrm{cm}^{-2}\right)$ for each element using a calibration with National Bureau of Standards (NBS) reference material. Minimal interference was caused by PTFE and Zeflour filters as seen in Fig. 1 (low background signal). In addition to locating iron-containing particles, calibrated data from these maps was used to characterize the association of other elements with iron. An energy scan (e.g. XANES analysis) was subsequently collected for iron-containing particles identified in microscopy mode (typically 30 iron-containing particles/filter). The X-ray energy scale was calibrated to the iron K-edge $(7112.0 \mathrm{eV})$ using an iron metal foil before XANES measurements were performed. The incident X-ray energy was varied from 7090 to $7180 \mathrm{eV}$ in $0.5 \mathrm{eV}$ increments using a monochromator for 
a $0.5-3.0 \mathrm{~s}$ dwell to produce an energy scan near the iron Kedge of a given iron-containing particle.

\subsection{XANES spectra analysis using ATHENA software (2.1.1)}

ATHENA software (version 2.1.1) was used to process the raw energy spectra. Individual energy scans were smoothed using a three-point algorithm for 10 iterations. The energy scans were subsequently normalized using the edge step normalization option to avoid mathematical discrepancies caused by directly dividing the fluorescence signal of incident X-ray beam by the signal in the upstream ionization chamber. The pre-edge centroid of the XANES spectra was the primary spectral feature used to determine oxidation state. The pre-edge centroid position was only determined from high intensity spectra (>5000 intensity counts: 103 spectra) to avoid any interferences caused by the low signal to noise ratio in low intensity spectra. The pre-edge feature was normalized by subtracting the pre-edge absorption from the background absorption, calculated by interpolating a cubic spline equation through the absorption $1 \mathrm{eV}$ before and after the pre-edge feature. A Gaussian equation was fit to the normalized pre-edge feature using peak fitting program in Igor software (version 6.1) to determine the pre-edge centroid position. Figure S1 provides a detailed demonstration on how the pre-edge centroid feature was extracted in this study. In addition, XANES energy scans of a wide range of $\mathrm{Fe}(\mathrm{II})$ and $\mathrm{Fe}(\mathrm{III})$ minerals (augite, pyrite, iron (II) oxalate, iron (II) sulfate, goethite, hematite, iron (III) sulfate, iron (III) sulfate) were collected at the 2-ID-D beamline under similar sampling conditions as ambient sample analysis during February 2010. Table S1 provides a detailed description (classification and origin) of each iron mineral standards. Powder from each iron mineral standard was mounted on aluminum sample stick using double-sided tape for analysis. Similar pre-edge centroid analysis was applied to XANES standard data of Fe minerals to compare to ambient sample data. Oxidation state was determined by the relationship between oxidation state and pre-edge centroid position. In this study, a linear equation was interpolated through $\mathrm{Fe}(\mathrm{II})$ (augite, pyrite, iron (II) sulfate, iron (II) oxalate) and $\mathrm{Fe}$ (III) (goethite, hematite, iron (III) oxalate and iron (III) sulfate) mineral data with the mean pre-edge centroid position of $\mathrm{Fe}(\mathrm{II})$ and $\mathrm{Fe}(\mathrm{III})$ minerals representing $0 \% \mathrm{Fe}$ (III) and $100 \% \mathrm{Fe}(\mathrm{III})$, respectively. The pre-edge centroid position determined from single particles was converted to \% $\mathrm{Fe}(\mathrm{II})$ content using this interpolation, using Eq. (1). Several studies have used a similar approach to convert pre-edge centroid position of K-edge XANES spectra of octahedralcoordinated $\mathrm{Fe}$ minerals into \% oxidation state (Bajt et al., 1994; Wilke et al., 2001).

$\% \mathrm{Fe}(\mathrm{II})=100-\frac{\text { Centroid Position }-7112.9}{0.0143}$

\subsection{Fractional iron solubility analysis}

Soluble iron on the filter samples was measured using the ferrozine technique by Stookey (1970), based on the absorption of light by the $\mathrm{Fe}$ (II)-ferrozine complex at $562 \mathrm{~nm}$ to quantify $\mathrm{Fe}(\mathrm{II})$ in solution. A DTMini-2 equipped with a dual deuterium and tungsten halogen bulb (Ocean Optics: Dunedin, Florida, USA) provided light in the UV/VIS range (200$800 \mathrm{~nm}$ ), and a USB2000 spectrophotometer (Ocean Optics: Dunedin, Florida, USA) was used for light absorption measurements. A flow-through $100 \mathrm{~cm}$ Liquid Waveguide Capillary Cell (LWCC) (World Precision Instruments: Sarasota, Florida, USA) provided a long liquid absorption path length to enhance measurement sensitivity. The spectrophotometer was calibrated using five ammonium Fe(II) sulfate standards ranging from 0 to $20 \mathrm{Fe}$ (II) ppb liquid concentration (typical $\left.r^{2}=0.9999\right)$ before and after soluble analysis. The deionized water sample leach used in this study showed minimal interference with the ambient sample $(<1 \%$ measurement interference).

Sample preparation and analysis used in this study are similar to the protocol described by Majestic et al. (2006) for the analysis of soluble iron on 24-h integrated filter samples. In our study, one half of the filter sample was placed in an acid-cleaned $30 \mathrm{ml}$ amber Nalgene bottle and was subsequently diluted by 15 to $20 \mathrm{ml}$ of de-ionized water $\left(>18.0 \mathrm{M} \Omega\right.$ ). $\mathrm{PM}_{2.5}$ was extracted into solution via $30 \mathrm{~min}$ of ultra-sonication. A $10 \mathrm{ml}$ aliquot of the extracted sample was filtered through a $0.45 \mu \mathrm{m}$ PTFE filter (Fisher Scientific: Pittsburgh, Pennsylvania, USA) to remove insoluble particles $(>0.45 \mu \mathrm{m}$ diameter) from the solution. Ferrozine $(5.1 \mathrm{mM})$ was added to the sample aliquot $(100 \mu \mathrm{l}$ ferrozine $/ 10 \mathrm{ml} \mathrm{sam}$ ple) and pulled through the LWCC after $10 \mathrm{~min}$ of incubation time. Light absorption was immediately measured at $562 \mathrm{~nm}$ (max light absorption of Fe(II)-Ferrozine complex) and $700 \mathrm{~nm}$ (background measurement) to yield a 10-min operationally-defined soluble $\mathrm{Fe}$ (II) measurement. Hydroxylamine (HA) was subsequently added to the remaining filtrate $(100 \mu \mathrm{HA} / 10 \mathrm{ml}$ sample) to reduce soluble $\mathrm{Fe}(\mathrm{III})$ to $\mathrm{Fe}(\mathrm{II})$. After $10 \mathrm{~min}$ of incubation time, the light absorption measurements were repeated following the same procedure as the $\mathrm{Fe}(\mathrm{II})$ measurements, yielding the total soluble iron (Fe(II) $+\mathrm{Fe}(\mathrm{III}))$ content of the filtrate. $\mathrm{Fe}(\mathrm{III})$ concentration was determined by subtraction of the $\mathrm{Fe}(\mathrm{II})$ soluble concentration from the total soluble iron concentration. The method limit of detection is estimated to be $0.11 \mathrm{ng} \mathrm{m}^{-3}$ (Majestic et al., 2006), which is well below soluble iron concentrations typically observed in urban aerosols.

Bulk total iron concentration was determined by micro Xray fluorescence measurements. In this approach, total iron measured on a given elemental map (typically $40 \times 40 \mu \mathrm{m}$ ) was multiplied by the total sample area divided by the elemental map area to determine the total iron concentration of the sample. When 2 or more elemental maps were collected for a given sample, the average of the total iron concentration 


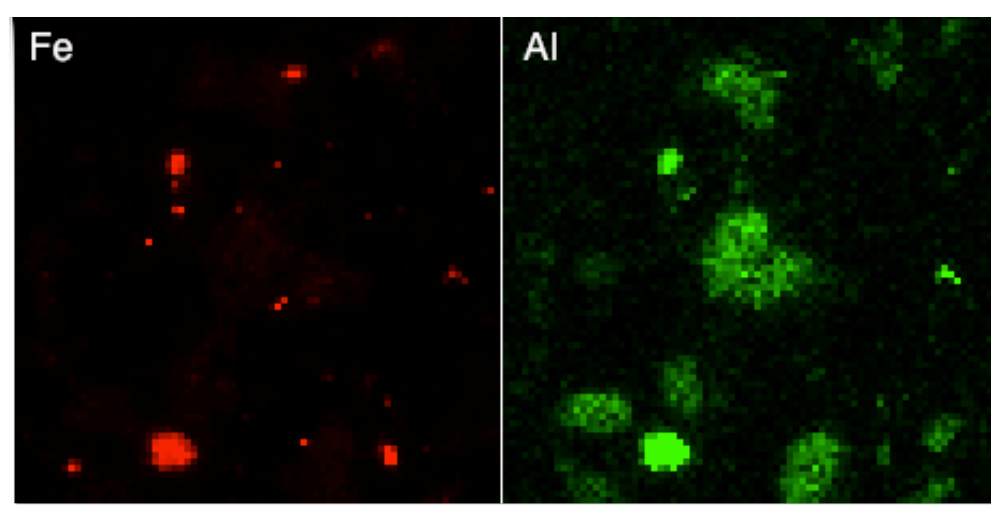

10 um

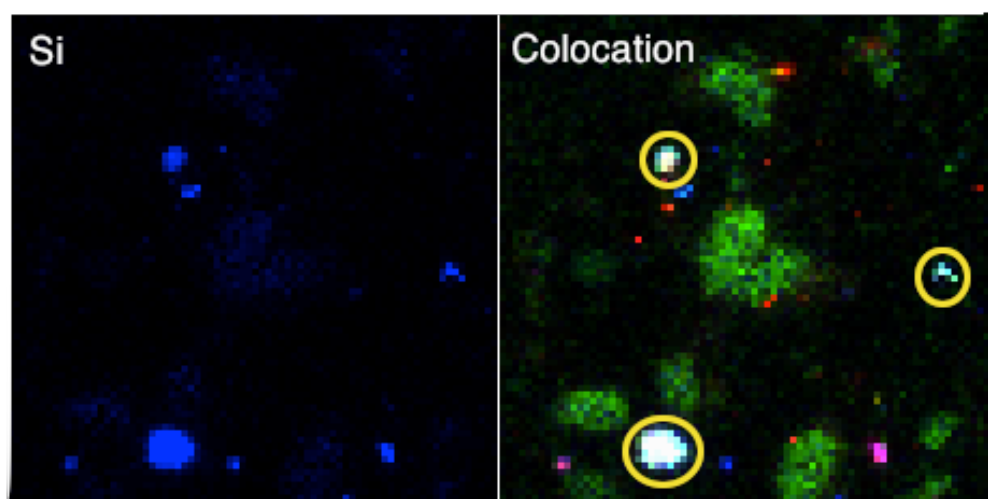

Fig. 1. Elemental maps $(30 \times 30 \mu \mathrm{m})$ of iron (red), aluminum (green), and silicon (blue) from South Dekalb 11/11/08 filter sample are presented. The fourth map is a colocation map, where the iron map is superimposed on aluminum and silicon maps. The white particles on the colocation plot indicate that iron, aluminum and silicon are concentrated in this area. The yellow circles on the colocation plot indicate 3 iron-containing particles that are enriched in aluminum and silicon.

from all elemental maps was used to determine the concentration of the sample using micro X-ray fluorescence measurements. Uncertainty was determined by the variability of total iron measured on different elemental maps for the same filter sample. In this study, there was moderate uncertainty (20-55\% standard deviation) associated with this measurement approach. These uncertainties were predominately associated with an uneven distribution of iron-containing particles on the filter. Fractional iron solubility was determined by normalizing soluble iron to total iron concentrations (e.g. soluble iron/total iron). The uncertainty in fractional iron solubility was estimated for each filter sample by propagating the error associated with soluble iron (1-3\%) and total iron (20-55\%) measurements.

\section{Results and discussion}

\subsection{Identification of iron-containing particles}

Using microscopic X-ray fluorescence, several areas were scanned on each urban and rural filter (1-4 maps per filter) to map out the spatial distribution and concentration of el- ements from aluminum to iron ( $\mathrm{Al}, \mathrm{Si}, \mathrm{P}, \mathrm{S}, \mathrm{Cl}, \mathrm{K}, \mathrm{Ca}, \mathrm{Ti}$, $\mathrm{V}, \mathrm{Cr}, \mathrm{Mn}$, and $\mathrm{Fe}$ ), referred to as elemental maps. Ironcontaining particles were identified in this analysis and were subsequently analyzed using XANES spectroscopy. In addition, the elemental maps provided data on the elements that were associated with iron in each particle. The combination of XANES spectra and microscopic X-ray fluorescence were used to characterize mineralogy. Figure 1 shows an example of iron, aluminum, and silicon elemental maps from the South Dekalb winter (11/11/08) filter. The fourth map presented in Fig. 1 shows the combined signal of all 3 elemental maps, indicating that both aluminum and silicon were associated with certain iron-containing particles in this sample.

\subsection{Iron oxidation state and mineralogy}

The pre-edge centroid position is the primary XANES spectra feature used to determine oxidation state and coordination chemistry of a given iron particle. It has been widely used to study iron in common minerals in soils (Prietzel et al., 2007; Wilke et al., 2001) and continental shelf particles in the ocean (Lam and Bishop, 2008). The energy of the pre- 
edge centroid position shifts anywhere from 1.4 to $3 \mathrm{eV}$ for a change of one valence electron (e.g. Fe(II) to Fe(III)).

The pre-edge centroid position was calculated for 103 particles (e.g. particles with high intensity spectra, $>5000$ raw counts) from the filter samples. Figure $\mathrm{S} 2$ shows the distribution of pre-edge centroid positions for single iron-containing particles from our samples. The pre-edge centroid position varied by $2.05 \mathrm{eV}$ among filter samples, ranging from 7112.75 to $7114.8 \mathrm{eV}$, with an average of $7114.0 \pm 0.3$, indicating significant oxidation state variability among our samples. The majority of the pre-edge centroid data for the urban and rural $\mathrm{Fe}$ particles falls between the centroid positions observed for $\mathrm{Fe}$ (II) and $\mathrm{Fe}$ (III) minerals (Fig. S2). Figure 2 shows corresponding percent $\mathrm{Fe}$ (II) to total $\mathrm{Fe}$ of single particles, based on pre-edge centroid position, on each of the 8 filters identified by sampling site and season. The Fe(II) fraction in single particles from both urban and rural sites was generally between 5 and $35 \%$, with the majority of the particles consisting of roughly $25 \% \mathrm{Fe}$ (II). The rural site (Fort Yargo) during the winter having a much higher Fe(II) content than the other filters, having a median $\mathrm{Fe}(\mathrm{II})$ content of $49 \%$. In addition, a few particles (e.g. 6 out of 103) had much lower pre-edge centroid positions (7112.75-7113.15eV) compared to the average of the entire dataset $(7114.0 \mathrm{eV})$, indicating iron in these particles was $100 \% \mathrm{Fe}$ (II). The Fe(II) content of single particles in this study is greater than those observed by Takahama et al. (2008), who showed a majority of marine and urban $\mathrm{Fe}$ aerosols exists as mixed-oxidation state agglomerations and surface-reduced particles, containing less than $10 \% \mathrm{Fe}(\mathrm{II})$. The results presented in our study compared to those of Takahama et al. (2008) suggests that large differences in iron redox state may characterize iron collected in different regions and seasons.

XANES spectra were similar for most of the Fe particles analyzed, regardless of season or site. Figure 3 a shows a XANES spectra observed for a typical oxidized and reduced particle $(100 \% \mathrm{Fe}$ (II) content, determined by pre-edge centroid position as seen in Fig. 3b, solid red line) observed in this study. Although the reduced particle shows a strong decreased shift in pre-edge and K-edge peak position, the shape of the spectra is similar to that of oxidized particles. Figure 4 shows the XANES spectra of a typical Fe particle (Sample 1 , dashed blue spectra) observed in this study compared to the XANES spectra of several Fe(II) and Fe(III) compounds. The XANES spectra, for the most part, closely follows the spectra of iron oxides (e.g. goethite and hematite, blue solid spectra) and lacks a resemblance to other classes of Fe minerals, such as silicates (augite and biotite), sulfides (pyrite), organics (Fe(II) and $\mathrm{Fe}(\mathrm{III})$ oxalate), and sulfates (Fe(III) sulfate), suggesting that the majority of $\mathrm{Fe}$ in urban aerosols is iron oxides. Further separation into specific Fe oxides was difficult, since differences in spectral features amongst this mineral class are very subtle. Most of the XANES spectra of the reduced particles follow the spectra of iron oxides with a shift in edge position; however, a few (2 out of 13) spectra

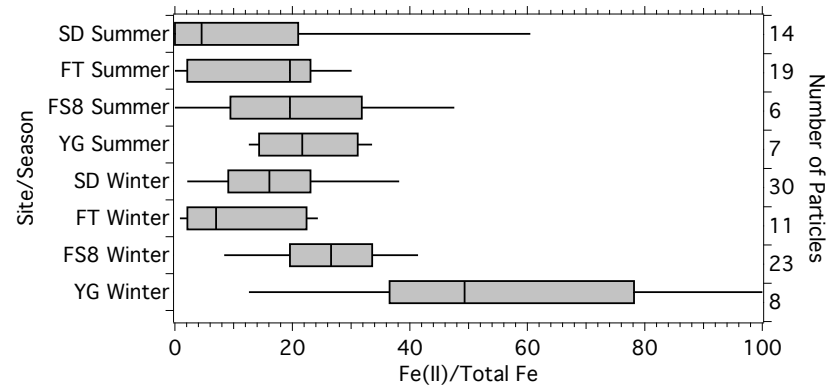

Fig. 2. Percentage of $\mathrm{Fe}(\mathrm{II})$ to total $\mathrm{Fe}(\mathrm{Fe}(\mathrm{II})+\mathrm{Fe}(\mathrm{III}))$ observed in single particles on filter samples are plotted for individual sites separated by season. 50th percentile (black line in box), 25th and 75th percentiles (lower and upper limit in box), 10th and 90th percentiles (lower and upper whiskers) of each dataset are represented in this graph. The right axis represents the number of data points represented for each sampling site/season.

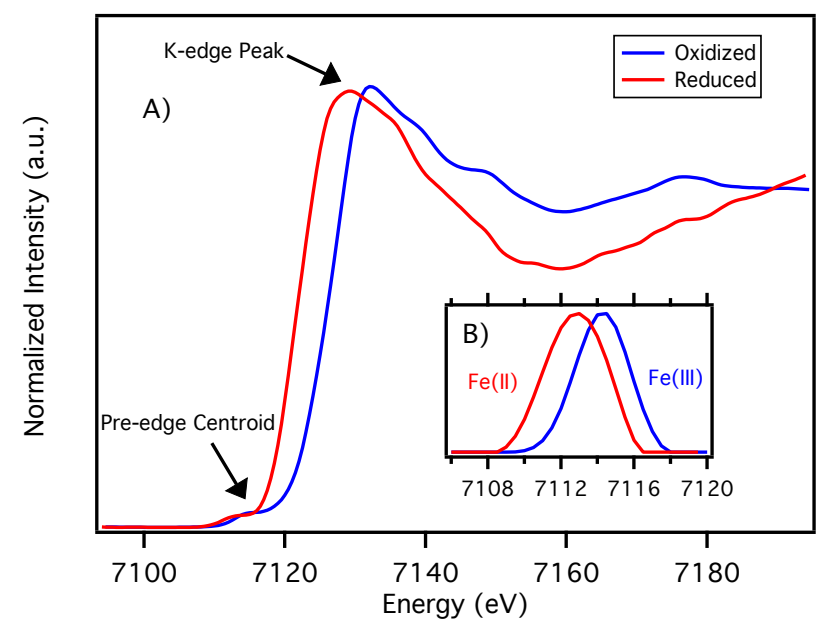

Fig. 3. (A) XANES spectra of a representative oxidized particle (blue line) and reduced Fe particle (red line) (B) Example of the normalized pre-edge centroid position of a representative oxidized particle (blue line) and reduced particle (red line).

of "more reduced" (pre-edge centroid position $<7113.6 \mathrm{eV}$ ) particles show a strong resemblance to silicates (e.g. biotite) shown in Fig. 4. The presence of Fe(II) (based on pre-edge centroid position) in iron-containing particles that appear to be iron oxides may suggest the presence of surface reduced species.

\subsection{Elemental composition of iron-containing particles: insight on mineralogy}

In addition to the XANES spectra, the elemental composition determined from microscopic X-ray fluorescence measurements of each iron-containing particle was investigated to further understand iron mineralogy. The concentration of each element from aluminum to iron was converted into 


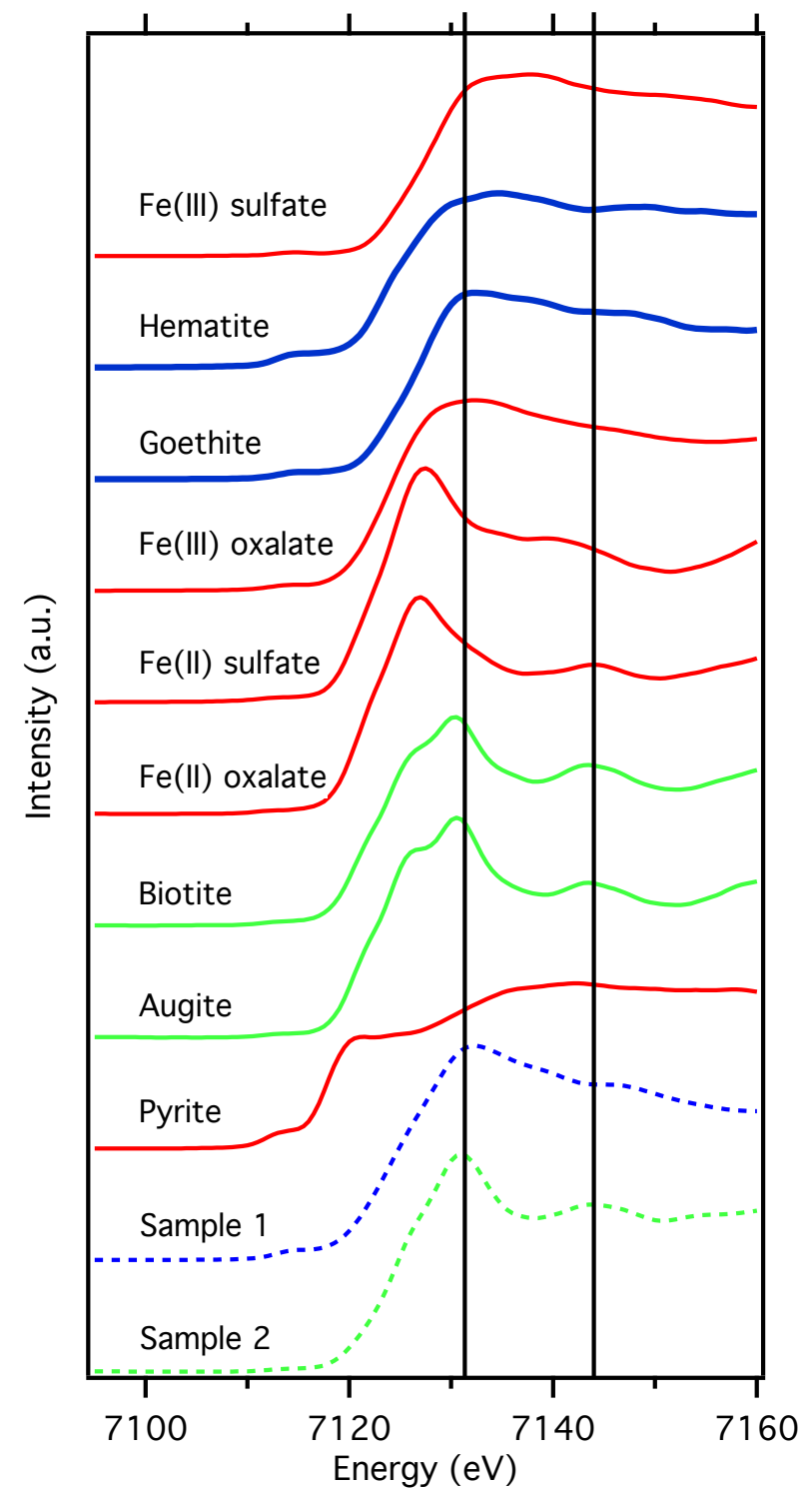

Fig. 4. Comparison of XANES sample spectra (dashed line) to the spectra of common Fe mineral standards (solid line). Two sample XANES spectra are plotted. Sample 1 (dashed blue line) represents a typical Fe urban oxidized particle corresponding to the majority of the data. Sample 2 (dashed green line) represents a reduced Fe particle observed in a few particles. Fe standards that resemble the ambient XANES sample spectra are plotted (iron oxide group (solid blue line) and iron-containing aluminosilicates (solid green line)). The vertical lines on the graph represent the energy where key XANES spectral features were identified.

molar units $\left(\mathrm{mol} \mathrm{cm}^{-2}\right)$ and compared to the iron molar concentration of each particle. Collectively, the iron data showed no strong correlation with any element $\left(r^{2}<0.20\right)$ for Fe mol vs. X mol, where $\mathrm{X}$ represents elements from $\mathrm{Al}$ to $\mathrm{Mn}$. Although a portion of single particle elemental data had low elemental molar concentrations, two clear trends emerged when $\mathrm{Fe}$ (mol) was plotted against $\mathrm{Al}(\mathrm{mol})$ as in Fig. 5.

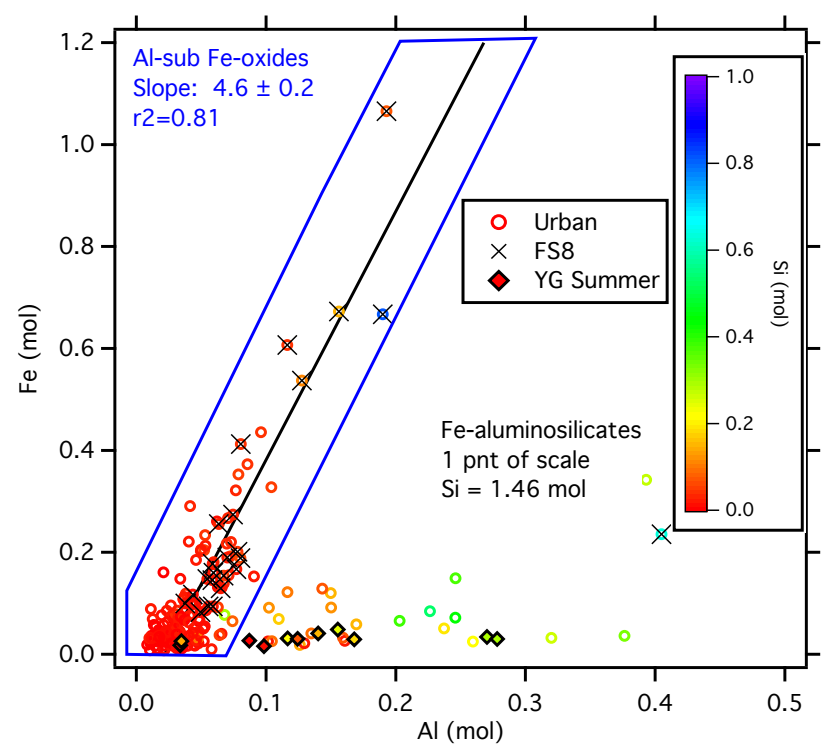

Fig. 5. Scatter plot of iron and aluminum molar concentration in iron-containing particles identified on urban and rural filters. The color scale denotes the silicon content in the particles. The blue outline represents single particles that are Al-substituted Fe-oxides. Particles from urban are represented by open colored circles. Particles from Fort Yargo summer and Fire Station 8 sites are represented by colored diamonds and black Xs, respectively.

The trends indicate that iron-containing particles could be divided into two groups. The first group, comprising the majority of particles (163 out of 221, 74\%) (Fig. 5: outlined by the blue area), were low in silicon ( $\mathrm{Si}$ molar concentration $<0.1$ ), yet contained a relatively consistent fraction of aluminum, in a 4.9:1 Fe:Al molar ratio $\left(r^{2}=0.81, p<0.05\right.$, e.g. within 0.05 statistical significance level). The aluminum content of these particles greatly exceeded trace aluminum levels that would be expected in pure iron oxide minerals, which ideally contain only $\mathrm{Fe}, \mathrm{O}$, and $\mathrm{OH}$. Iron is commonly substituted by cations of similar size and charge, like aluminum, in iron oxide matrices, and is often observed in crustal particles (Cornell and Schwertmann, 2003). For example, aluminumsubstitution observed in goethite can vary from $0-33 \%$ on a molar basis. This data coupled with the XANES spectra suggest that these particles are likely Al-substituted Fe-oxides.

The second group of particles ( 26 out of $221,12 \%$ ), shown in Fig. 5, is characterized by lower iron concentrations and enhanced levels of silicon ( $\mathrm{Si}$ molar concentration $>0.1$ ) and aluminum (Al molar concentration $>0.1$ ) relative to the first group of particles, referred to here as Fe-aluminosilicates. The silicon content of these particles strongly correlates with aluminum, with a $1.4 \mathrm{Si} / \mathrm{Al}$ molar ratio, $\left(r^{2}=0.72, p<\right.$ 0.05 ), which compares well to $\mathrm{Si} / \mathrm{Al}$ molar ratios of common aluminosilicate minerals (typically 1 to 4 ) (Deer et al., 1978). Though the XANES spectra of a few of these particles (2 out of 26 particles, Sample 2 spectra in Fig. 4) resembled spectra 
of common iron-containing aluminosilicates, the majority of the spectra for these particles ( 24 out of 26 particles, Sample 1 spectra in Fig. 4) are best matched by the common iron oxides. This result indicates that a majority of these particles contain a significant amount of iron in the form of oxides, which are oxidation products of Fe-aluminosilicates (Deer et al., 1978). The Si/Al molar ratio coupled with XANES spectra, which indicates iron oxide, suggests these particles are processed Fe-aluminosilicates. The remaining $14 \%$ of iron-containing particles did not correspond to trends observed in either $\mathrm{Al}$-substituted $\mathrm{Fe}$-oxides or processed $\mathrm{Fe}$ aluminosilicates, thus, their mineralogy was undetermined.

\subsection{Mineralogy of iron-containing particles at different sites}

Figure 5 also shows the distribution of Al-substituted Feoxides and processed $\mathrm{Fe}$-aluminosilicates particles at urban and rural sites. Al-substituted Fe-oxides and processed $\mathrm{Fe}$ aluminosilicates are observed at both urban and rural sites. For the urban sites, South DeKalb and Fort McPherson, show a mixture of both types of particles, regardless of season, while Fire Station 8 particles were exclusively associated with Al-substituted Fe-oxides for both winter and summer (Fig. 5, with the exception of 1 point). In addition, Fort Yargo contained both types of particles during the winter, but was exclusively associated with processed $\mathrm{Fe}$-aluminosilicates in the summer. The predominance of $\mathrm{Al}$-substituted $\mathrm{Fe}$-oxide and processed $\mathrm{Fe}$-aluminosilicate particles from our samples is consistent with a previous study showing iron aerosols collected in an urban area in Germany over a 5-month period are comprised of $78 \%$ iron oxides and $22 \%$ Fe silicates (Hoffmann et al., 1996). Though the elemental $\mathrm{Fe}, \mathrm{Al}$, and $\mathrm{Si}$ molar concentration for a portion of single iron-containing particles was low (as shown in Fig. 5), thus, mineralogy was difficult to discern, our results clearly demonstrate that variations in iron mineralogy do exist in urban and rural $\mathrm{PM}_{2.5}$. However, analysis of more samples (e.g. $>2$ samples per site) is necessary to establish reasonable spatial and seasonal trends in bulk iron mineralogy.

\subsection{Investigating factors that control fractional iron solubility}

Soluble and total iron content was determined for all the urban and rural filters for different seasons using ferrozine and micro X-ray fluorescence measurements. Results from these analyses are presented in Table 2. A significant amount of variability was observed in soluble iron on filter samples collected in urban areas, with the concentrations ranging from 3.4 to $47.9 \mathrm{ng} \mathrm{m}^{-3}$, while soluble iron content on samples from rural areas was comparatively low ranging from 4.3 to $5.8 \mathrm{ng} \mathrm{m}^{-3}$. These concentrations are typical of fractional iron solubility in urban and rural aerosol in the Midwestern US (Majestic et al., 2007). A wide range of total iron concentrations was also observed on the samples, ranging from 15 and $1734 \mathrm{ng} \mathrm{m}^{-3}$. Although the total iron calculated had moderate uncertainty (Table 2), the majority (e.g. 7 out of 8) of the iron from our samples was within the range (mean \pm standard deviation) of typical iron concentrations observed in urban and rural sites in the Southeastern US (Table S2). However, the iron concentration $\left(1734 \mathrm{ng} \mathrm{m}^{-3}\right)$ observed at the urban site Fire Station 8 during the winter was much higher than typical concentrations observed in Atlanta, GA and urban Southeastern US sites. Although this concentration was observed at Fire Station 8, which is characterized as an urban Atlanta site with poor air quality (e.g. PM mass concentration generally $30 \%$ greater than other Atlanta sampling sites (Trail, 2010)), the total concentration was probably a direct result of an uneven distribution of iron on the filter. Iron on this particular elemental map may have been concentrated with respect to the remaining sample area, leading to an overestimation of total iron collected on the filter. This result reflects the moderate uncertainties associated with calculating absolute concentrations of aerosol components using synchrotron-based technology. With the exception of the Fire Station 8 winter sample, the majority of data are within the acceptable range of typical iron aerosol concentrations in the Southeastern US. However, for further statistical analysis, the Fire Station 8 sample was omitted.

To investigate solubility in relation to other variables (e.g. iron speciation), soluble iron concentration was normalized to total iron content determined by micro X-ray fluorescence measurements to yield fractional iron solubility (e.g. soluble iron/total iron content). Fractional iron solubility was between 2 and $38 \%$ (mean: $15.8 \pm 11.8 \%$ ) at individual urban and rural sites during different seasons (individual site data in Table 2). Though moderate uncertainty was associated with these solubility estimates (23-55\% error, predominately due to total iron measurements), it did not appear to have a significant impact on the trends observed in solubility (see Table 2 and Fig. 6). Overall, the fractional solubility levels observed in this study compare reasonably well to those found in common iron oxide $(<1 \%)$ and silicate (3-6\%) minerals (Journet et al., 2008; Schroth et al., 2009), suggesting our mineralogy data correspond well to expected fractional solubility levels. Fractional iron solubility was compared to a number of variables to assess their influence. No clear relationship was found between fractional iron solubility and total iron content $\left(r^{2}=0.004, p>0.05\right)$. These results are consistent with several studies, which have reported fractional iron solubility as an inconsistent fraction of total iron, ranging anywhere between 0 to $80 \%$ of total iron (Baker and Croot, 2010, Mahowald et al., 2005). In addition, speciation (oxidation state and mineralogy) was also compared to fractional iron solubility. Figure 6 shows a moderate relationship between fractional iron solubility and median single particle $\mathrm{Fe}$ (II) data $\left(r^{2}=0.56\right.$, Table 2$)$; however, this trend is not statistically robust $(p>0.05)$. In addition, given the limitations of this analysis (large variations 
Table 2. Solubility Results for Urban and Rural Filters.

\begin{tabular}{|c|c|c|c|c|c|c|c|c|}
\hline Site & Season & $\begin{array}{l}\text { Soluble Fe(II })^{\mathrm{a}} \\
\left(\mathrm{ng} \mathrm{m}^{-3}\right)\end{array}$ & $\begin{array}{l}\text { Soluble Fe }{ }^{\mathrm{a}, \mathrm{b}} \\
\left(\mathrm{ng} \mathrm{m}^{-3}\right)\end{array}$ & $\begin{array}{l}\text { Total Fe }{ }^{c} \\
\left(\mathrm{ng} \mathrm{m}^{-3}\right)\end{array}$ & $\mathrm{N}_{\text {maps }} \mathrm{d}$ & $\begin{array}{l}\text { Total } \\
\mathrm{Fe}(\mathrm{II})^{\mathrm{e}} / \text { Total Fe }\end{array}$ & $N_{\text {part }}^{\mathrm{g}}$ & $\begin{array}{l}\text { Soluble } \mathrm{Fe}^{\mathrm{b}} / \\
\text { Total } \mathrm{Fe}^{\mathrm{h}}\end{array}$ \\
\hline \multicolumn{9}{|c|}{ Rural Sites } \\
\hline \multirow{2}{*}{ Fort Yargo } & Summer & $2.0 \pm 0.08$ & $4.3 \pm 0.17$ & $78.0 \pm 43.1$ & 2 & $0.47 \pm 0.09$ & 7 & $0.055 \pm 0.03$ \\
\hline & Winter & $4.9 \pm 0.2$ & $5.8 \pm 0.23$ & $15.4 \pm 3.6$ & 3 & $0.83 \pm 0.28$ & 8 & $0.38 \pm 0.09$ \\
\hline \multicolumn{9}{|c|}{ Urban Sites } \\
\hline \multirow{2}{*}{ Fire Station 8} & Summer & $4.6 \pm 0.06$ & $13.6 \pm 0.18$ & 52.6 & 1 & $0.45 \pm 0.16$ & 6 & $0.26 \pm 0.10$ \\
\hline & Winter & $30.0 \pm 1.0$ & $49.9 \pm 1.64$ & $1734^{e}$ & 1 & $0.50 \pm 0.12$ & 23 & $0.028 \pm 0.01$ \\
\hline \multirow{2}{*}{ Fort McPherson } & Summer & $4.0 \pm 0.04$ & $12.9 \pm 0.14$ & $88.1 \pm 32.2$ & 2 & $0.34 \pm 0.17$ & 19 & $0.15 \pm 0.05$ \\
\hline & Winter & $6.9 \pm 0.09$ & $12.2 \pm 0.16$ & 96.5 & 1 & $0.49 \pm 0.10$ & 11 & $0.13 \pm 0.05$ \\
\hline \multirow{2}{*}{ South Dekalb } & Summer & $5.8 \pm 0.1$ & $10.8 \pm 0.22$ & $174.0 \pm 86.3$ & 2 & $0.40 \pm 0.23$ & 14 & $0.062 \pm 0.05$ \\
\hline & Winter & $3.0 \pm 0.06$ & $3.4 \pm 0.07$ & $174.0 \pm 39.5$ & 3 & $0.39 \pm 0.09$ & 30 & $0.020 \pm 0.004$ \\
\hline
\end{tabular}

${ }^{a}$ Measured by ferrozine technique

${ }^{\mathrm{b}}$ Soluble Fe $=$ Soluble Fe(II) + Soluble Fe(III)

${ }^{\mathrm{c}}$ Measured by XANES spectroscopy

d Number of XANES elemental maps used to determine total Fe concentration

${ }^{\mathrm{e}}$ Measured by XANES spectroscopy, mean value of single particle oxidation state calculated for each filter

${ }^{\mathrm{f}}$ Outlier: Concentration is outside the standard deviation of typical total $\mathrm{PM}_{2.5}$ Fe concentration measured on filters collected in urban and rural areas in Southeastern US (seen in Table S2)

g Number of single particles analyzed using XANES

${ }^{\mathrm{h}}$ Uncertainty propagated by the error in soluble and total iron measurements

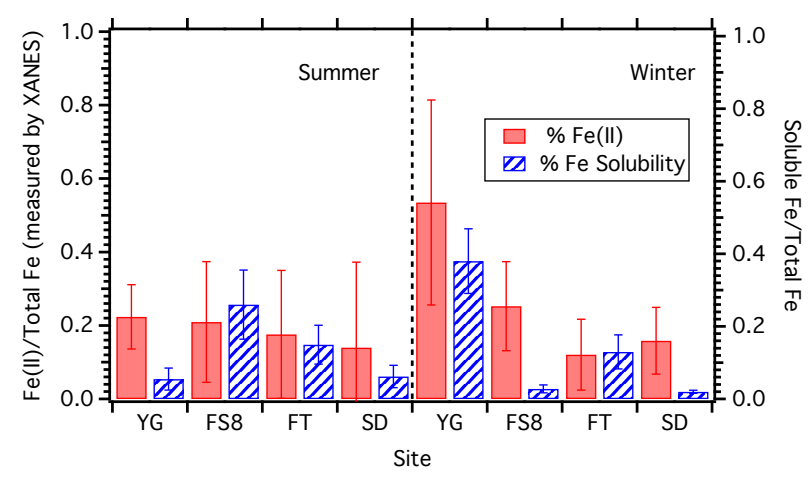

Fig. 6. Total (soluble + insoluble) $\mathrm{Fe}(\mathrm{II})(\mathrm{Fe}(\mathrm{II}) / \mathrm{Total} \mathrm{Fe})$ measured by XANES (red bars) and fractional iron solubility (blue hatched bars) content in each filter sample. Error bars represent the $\pm 1 \sigma$.

observed in single particle $\mathrm{Fe}(\mathrm{II})$ content and small sample size), it is difficult to determine whether or not this moderate trend actually exists. However, our data suggests that $\mathrm{Fe}(\mathrm{II})$ content may not significantly impact fractional iron solubility. The absence of trend with speciation is more profound when fractional iron solubility is compared to variations in mineralogy observed at different sites. The most significant difference in the mineralogy of particles in this study was observed between Fire Station 8 site (summer and winter) and the Fort Yargo site during the summer, where particles were exclusively associated with $\mathrm{Al}$-substituted $\mathrm{Fe}$ oxides and processed Fe-aluminosilicates, respectively. No significant difference in fractional solubility was observed at these two sites, suggesting iron speciation is not the only factor influencing solubility.

Although no clear relationship between fractional iron solubility and abundance of major iron phases was observed in this study, several laboratory experiments on iron-containing crustal and oil fly-ash particles provide evidence supporting this relationship (Journet et al., 2008; Schroth et al., 2009). One reason explaining the lack of trend in this study is the two dominant mineral phases observed (e.g. Al-substituted Fe-oxides and processed Fe-aluminosilicates) have similar fractional iron solubility levels (iron oxides $(<1 \%)$ and iron silicates (3-6\%) (Journet et al., 2008; Schroth et al., 2009)). Thus, various mixtures of these two phases are not expected to yield large variations in solubility, which is the case in our data where fractional iron solubility is low and only slightly variable among different sites. A stronger association between mineralogy and solubility, however, is expected in areas where highly soluble iron minerals (e.g. iron sulfate) are the dominant source of iron in aerosols. For instance, iron oxides and silicates in crustal particles $(<6 \%$ fractional solubility) are significantly less soluble than iron sulfates in oil fly ash ( $\sim 80 \%$ fractional solubility) (Journet et al., 2008; Schroth et al., 2009). No iron sulfates, which are observed in anthropogenic combustion sources, were observed in this study. However, Liu et al. (2005) showed that various anthropogenic combustion sources comprise a small, but measureable component $(<10 \%)$ of Atlanta $\mathrm{PM}_{2.5}$. Given the limited single particle analysis used in this study (e.g. limited 
sample size), the small fraction of iron-containing particles from anthropogenic combustion sources may not have been detected. This small fraction of iron sulfates may have contributed to the somewhat enhanced solubility levels observed in our data at several sites $(>6 \%)$ compared to that of pure iron oxide $(<1 \%)$ or silicate $(3-6 \%)$ minerals. In addition, low levels of iron sulfates may also explain the minor differences in solubility levels between different sites and seasons.

Another factor possibly affecting the relationship between mineralogy and solubility in this study is that ambient aerosol may have undergone a variety of atmospheric processes altering its chemical and physical properties. Oakes et al. (2010) showed evidence for enhancements in Fe(II) aerosol solubility in acidic sulfate plumes in Georgia. Secondary sulfate is a significant portion of particle mass $(\sim 50 \%)$ in the Southeastern US (Liu et al., 2005), which can form sulfuric acid in the absence of sufficient neutralizing cations. In this study, acid-processing mechanisms may play a more central role than speciation or work synergistically with speciation to influence iron solubility. This would be consistent with Shi et al. (2011) who demonstrated that fractional iron solubility, in dust aerosols is highly sensitive to particle acidity (e.g. acid-processing mechanisms) and less dependent on other factors (e.g. particle source/mineralogy and size). In addition to acid-processing mechanisms, particle size can play an important role in fractional iron solubility. In this study, the size range of particles was limited (between $0.4-2.5 \mu \mathrm{m}$ in aerodynamic diameter, lower size resolution based on the spot size of X-ray beam), and minor differences in particle size were difficult to detect. Thus, the relationship between particle size and fractional iron solubility could not be evaluated. More detailed studies involving particle $\mathrm{pH}$, size, iron speciation, and fractional iron solubility are necessary to better understand factors that influence iron solubility in ambient aerosols.

While the results of this study clearly demonstrate the value of single particle synchrotron-based analysis in determining aerosol speciation, there are uncertainties associated with this approach. One uncertainty is representing bulk sample properties with single particle measurements, which comprise a limited portion of the sample. Though the results in this study showed unique variations in single particle iron speciation, these properties may not be representative of the entire sample, making it difficult to compare to other bulk properties (e.g. fractional iron solubility). The results of this study show the need for both single particle and bulk iron speciation in order to fully understand its impact on fractional iron solubility in aerosols.

\subsection{Atmospheric implications: insight on human health toxicity}

Fine aerosols that contain iron have been shown to generate toxic levels of ROS (Shafer et al., 2010; Zhang et al., 2008). Recent experiments have related toxicity to iron oxidation state in nanoparticles (diameters smaller than $100 \mathrm{~nm}$ ). Reduced iron in nanoparticles, either present as water-soluble or crystalline $\mathrm{Fe}(0)$ or $\mathrm{Fe}(\mathrm{II})$, has been shown to be more efficient than $\mathrm{Fe}$ (III) in ROS generation (Auffan et al., 2008; Keenan et al., 2009). For example, Auffan et al. (2008) showed oxidation of $\mathrm{Fe}(0)$ and $\mathrm{Fe}(\mathrm{II})$ oxides (e.g. magnetite) immediately produce ROS, while $\mathrm{Fe}(\mathrm{III})$ oxides (e.g. maghemite) produced little to no ROS within one hour. Although particles in this study are larger (approximately 0.4 $2.5 \mu \mathrm{m}$ ) and presumably less reactive than nanoparticles due to less surface area per mass, the same mechanisms are likely involved in the formation of ROS via iron-mediated pathways (e.g. Fenton reactions). Thus, Fe(II) is a plausible precursor for immediate production of ROS in $\mathrm{PM}_{2.5}$. The ambient particles we investigated contained various amounts of $\mathrm{Fe}(\mathrm{II})$ and $\mathrm{Fe}(\mathrm{III})$, with the $\mathrm{Fe}(\mathrm{II})$ fraction accounting for approximately $\sim 5$ to $35 \%$ of total iron. These results indicate that a significant portion of iron-containing particles is in a redox state that can produce ROS immediately. Although $\mathrm{Fe}(\mathrm{II})$ is not always soluble in ambient aerosols (a factor strongly associated with ROS formation), particlebound $\mathrm{Fe}(\mathrm{II})$ may interact with specific species (e.g. acidic aerosol) during atmospheric transit, promoting its solubility.

\section{Conclusions}

We present a novel approach for exploring the speciation of iron in single atmospheric fine particles collected in urban and rural regions during different seasons using synchrotronbased XANES spectroscopy and microscopic X-ray fluorescence techniques. The majority of the particles contained mixtures of oxidized ( $\mathrm{Fe}(\mathrm{III}))$ and reduced ( $\mathrm{Fe}(\mathrm{II}))$ iron, with an average of $25 \%$ of the iron present as $\mathrm{Fe}(\mathrm{II})$. Particulate iron from urban and rural sites in Georgia was observed primarily in two phases, Al-substituted Fe-oxides and processed Fe-aluminosilicates. Though the composition of these aerosols was substantially different than pure minerals, it was consistent with modifications that occur during oxidation processes. Based on the techniques used in this study, variations in the abundance of $\mathrm{Al}$-substituted $\mathrm{Fe}$-oxides and processed Fe-aluminosilicates did not coincide with the fractional iron solubility. Fractional iron solubility may be controlled by iron minerals from minor sources, for example, anthropogenic combustion sources of iron sulfates that were not detected by XANES as a component of overall mineralogy. In addition, other physical or chemical properties (e.g. particle acidity or size) may act in conjunction with mineralogy to influence solubility. These other properties may control the toxicity of iron-containing particles more than bulk mineralogy. 


\section{Supplementary material related to this article is available online at: \\ http://www.atmos-chem-phys.net/12/745/2012/ acp-12-745-2012-supplement.pdf.}

Acknowledgements. Financial support was provided by from the U.S. National Science Foundation through grant ATM-0802237 and the Environmental Protection Agency STAR Research Grant RD-83283501. The views expressed in this manuscript are solely those of the authors and EPA does not endorse any of the products or commercial services mentioned in the publication.

Edited by: A. Nenes

\section{References}

Auffan, M., Achouak, W., Rose, J., Roncato, M., Chaneac, C., Waite, D. T., Masion, A., Woicik, J. C., Wiesner, M. R., and Bottero, J.: Relation between redox state of iron-based nanoparticles and their cytotoxicity toward escherichia coli, Environ. Sci. Technol. 42, 6730-6735, 2008.

Bajt, S., Sutton, S. R., and Delaney, J. S.: X-ray microprobe analysis of iron oxidation states in silicates and oxides using X-ray absorption near edge structure (xanes), Geochim. Cosmochim. Ac., 58, 5209-5214, 1994.

Baker, A. R. and Croot, P. L.: Atmospheric and marine controls on aerosol iron solubility in seawater, Mar. Chem., 120, 4-13, 2010

Baker, A. R. and Jickells, T. D.: Mineral particle size as a control on aerosol iron solubility, Geophys. Res. Lett., 33, doi:10.1029/2006GL026557, 2006.

Butler, A. J., Andrew, M. S., and Russell, A. G.: Daily sampling of $\mathrm{PM}_{2.5}$ in atlanta: Results of the first year of the assessment of spatial aerosol composition in Atlanta study, J. Geophys. Res.Atmos., 108, D7, doi:10.1029/2002JD002234, 2003.

Chuang, P. Y., Duvall, R. M., Shafer, M. M., and Schauer, J. J.: The origins of water soluble particulate iron in Asian outflow, Geophys. Res. Lett., 32, L07813, doi:0.1029/2004GL021946, 2005.

Cornell, R. M. and Schwertmann, U.: The iron oxides: Structure, properties, reactions, occurences and uses, Wiley-VCH Verlag GmbH\& Co. KGaA, Weinheim, 2003.

Costa, D. L. and Dreher, K. L.: Bioavailable transition metals in particulate matter mediate cardiopulmonary injury in healthy and compromised animal models, Environ. Health Persp., 105, 10531060, 1997.

Cwiertny, D. M., Baltrusaitis, J., Hunter, G. J., Laskin, A., Scherer, M. M., and Grassian, V. H.: Characterization and acid-mobilization study of iron-containing mineral dust source materials, J. Geophys. Res., 113, D05202, doi:10.1029/2007JD00932, 2008.

Deer, W. A., Howie, R. A., and Zussman, J.: An introduction to the rock forming minerals.Longman Group Limited, London, UK, 1978.

Furukawa, T. and Takahashi, Y.: Oxalate metal complexes in aerosol particles: implications for the hygroscopicity of oxalatecontaining particles, Atmos. Chem. Phys., 11, 4289-4301, doi:10.5194/acp-11-4289-2011, 2011
Hoffmann, P., Dedik, A. N., Ensling, J., Weinbruch, S., Weber, S., Sinner, T., Gutlich, P., and Ortner, H. M.: Speciation of iron in atmospheric aerosol samples, J. Aerosol Sci., 27, 325-327, 1996.

Ingall, E. D., Brandes, J. A., Diaz, J. M., de Jonge, M. D., Paterson, D., McNulty, I., Elliot, W. C., and Northrup, P.: Phosphorus Kedge XANES spectroscopy of mineral standards, J. Synchrotron. Radiat., 18, 18, doi:10.1107/S0909049510045322, 2011.

Johansen, A. M., Siefert, R., and Hoffmann, M. R.: Chemical composition of aerosols collected over the tropical north atlantic ocean, J. Geophys. Res.-Atmos., 105, 15277-15312, 2000.

Journet, E., Desboeufs, K. V., Caquineau, S., and Colin, J. L.: Mineralogy as a critical factor of dust iron solubility, Geophys. Res. Lett., 35, L07805, doi:10.1029/2007GL031589, 2008.

Keenan, C. R., Goth-Goldstein, R., Lucas, D., and Sedlak, D. L.: Oxidative stress induced by zero-valent iron nanoparticles and $\mathrm{Fe}(\mathrm{II})$ in human bronchial epithelial cells, Environ. Sci. Technol., 43, 4555-4560, 2009.

Kelly, F. J.: Oxidative stress: Its role in air pollution and adverse health effects, Occup. Environ. Med., 60, 612-616, 2003.

Lam, P. J. and Bishop, J. K.: The continental margin is a key source of iron to the hnlc north pacific ocean, Geophys. Res. Lett., 35, L07608, doi:10.1029/2998GL033294, 2008.

Liu, W., Wang, Y. H., Russell, A., and Edgerton, E. S.: Atmospheric aerosol over two urban-rural pairs in the southeastern united states: Chemical composition and possible sources, Atmos. Environ., 39, 4453-4470, 2005.

Mahowald, N., Baker, A. R., Bergametti, G., Brooks, N., Duce, R. A., Jickells, T. D., Kubilay, N., Prospero, J. M., and Tegen, I.: Atmospheric global dust cycle and iron inputs to the ocean, Global Biogeochem. Cy., 19, GB4025, doi:10.1029/2004GB002402, 2005.

Majestic, B. J., Schauer J. J., and Shafer, M. M.: Development of wet chemical method for the speciation of iron in atmospheric aerosols, Environ. Sci. Technol., 40, 2346-2351, 2006.

Majestic, B. J., Schauer, J. J., and Shafer, M. M.: Application of synchrotron radiation for measurement of iron red-ox speciation in atmospherically processed aerosols, Atmos. Chem. Phys., 7, 2475-2487, doi:10.5194/acp-7-2475-2007, 2007.

Marcus, M. A., Westphal, A. J. and Fakra, S. C.: Classification of Fe-bearing species from k-edge xanes data using two parameter correlation plots, J. Synchrotron. Radiat., 15, 463-468, 2008.

Meskhidze, N., Chameides, W. L., and Nenes, A.: Iron mobilization in mideral dust: Can anthropogenic SO2 emissions affect ocean productivity?, Geophys. Res. Lett., 30, 21, doi:10.1029/2003GL018035, 2003.

Oakes, M., Rastogi, N., Majestic, B. J., Shafer, M., Schauer, J. J., Edgerton, E. S., and Weber, R. J.: Characterization of soluble iron in urban aerosols using near-real time data, J. Geophys. Res.-Atmos., 115, D15302, doi:10.1029/2009JD012532, 2010.

Paris, R., Desboeufs, K. V., and Journet, E.,: Variability of dust iron solubility in atmospheric waters: investigateion of the role of oxalate organic complexation, Atmos. Environ., 45, 6510-6517, 2011.

Pehkonen, S. O., Siefert, R., Erel, Y., Webb, S., and Hoffmann, M. R.: Photoreduction of iron oxyhydroxides in the presence of important atmospheric organic compounds, Environ. Sci. Technol., 27, 2056-2062, 1993.

Prietzel, J., Thieme, J., Eusterhues, K., and Eichert, D.: Iron speciation in soils and soil aggregates by synchrotron-based $\mathrm{x}$ - 
ray microspectroscopy (xanes, mu-xanes), Eur. J. Soil. Sci., 58, 1027-1041, 2007.

Schroth, A. W., Crusius, J., Sholkovitz, E. R., and Bostick, B. C.: Iron solubility driven by speciation in dust sources to the ocean, Nat. Geosci., 2, 337-340, 2009.

See, S. W., Wang, Y. H., and Balasubramanian, R.: Contrasting reactive oxygen species and transition metal concentrations in combustion aerosols, Environ. Res., 103, 317-324, 2007.

Shafer, M. M., Perkins, D. A., Antkiewicz, D. S., Stone, E. A., Quiraishi, T. A., and Schauer, J. J.: Reactive oxygen species acitivity and chemical speciation of size-fractionated atmospheric particlate matter from lahore, pakistan: An important role for transition metals, J. Environ. Monitor., 12, 704-415, 2010.

Shi, Z., Krom, M. D., and Bonneville, S.: Formation of iron nanoparticles and increase in iron reactivity in mineral dust during simulated cloud processing, Environ. Sci. Technol., 43, 6592-6596, 2009.

Shi, Z., Bonneville, S., Krom, M. D., Carslaw, K. S., Jickells, T. D., Baker, A. R., and Benning, L. G.: Iron dissolution kinetics of mineral dust at low $\mathrm{pH}$ during simulated atmospheric processing, Atmos. Chem. Phys., 11, 995-1007, doi:10.5194/acp11-995-2011, 2011a.

Shi, Z. B., Woodhouse, M. T., Carslaw, K. S., Krom, M. D., Mann, G. W., Baker, A. R., Savov, I., Fones, G. R., Brooks, B., Drake, N., Jickells, T. D., and Benning, L. G.: Minor effect of physical size sorting on iron solubility of transported mineral dust, Atmos. Chem. Phys., 11, 8459-8469, doi:10.5194/acp-11-84592011, 2011b.

Smith, K. R. and Aust, A. E.: Mobilization of iron from urban particulates leads to generation of reactive oxygen species in vitro and induction of ferritin synthesis in human lung epithlial cells, Chem. Res. Toxicol., 10, 828-834, 1997.
Stookey, L. L.: Ferrozine - a new spectrophotometric reagent for iron, Anal. Chem., 42, 779-781, 1970.

Takahama, S., Gilardoni, S. and Russell, L. M:. Single-particle oxidation state and morphology of atmospheric iron, J. Geophys Res.-Atmos., 113, D22202, doi:10.1029/2009JD009810, 2008.

Valavanidas, A., Fiotakis, K., and Viachogianni, T.: Airborne particulate matter and human health: Toxicological assessment and importance of size and composition of particle for oxidative damage and carcinogenic mechanisms, J. Environ. Sci. Heal. C, 26, 339-362, 2008.

Vidrio, E., Jung, H., and Anastasio, C.: Generation of hydroxyl radicals from dissolved transition metals in surrogate lung fluid solutions, Atmos. Environ., 42, 4369-4379, 2008.

Werner, M. L., Nico, P. S., Marcus, M. A., and Anastasio, C.: Use of micro-xanes to speciate chromium in airborne fine particles in the sacramento valley, Environ. Sci. Technol., 41, 4919-4924, 2007.

Wilke, M., Farges, F., Petit, P., Brown Jr, G. E., and Martin, F.: Oxidation state and coordination of fe in minerals: An Fe kxanes spectroscopic study, American Mineralogist., 86, 714730, 2001.

Zhang, Y., Schauer, J., Shafer, M. M., Hannigan, M. P., and Dutton, S. J.: Source apportionment of in vitro reactive oxygen species bioassay activity from atmospheric particulate matter, Environ. Sci. Technol., 42, 7502-7509, 2008.

Zhuang, G., Yi, Z., Duce, R. A., and Brown, P. R.: Link between iron and sulphur cycles suggested by detection of fe(ii) in remote marine aerosols, Nature, 355, 537-539, 1992. 